\title{
Ressonâncias Entre a Abordagem da Enação e a Psicologia Clínica
}

\section{Resonances Between Enactive Approach and Clinical Psychology}

\section{Resonancias entre la Abordaje de la Enacción y la Psicología Clínica}

\author{
Veronica Torres Gurgel* \\ Universidade Federal do Rio de Janeiro - UFRJ, Rio de Janeiro, Rio de Janeiro, Brasil \\ Virginia Kastrup** \\ Universidade Federal do Rio de Janeiro - UFRJ, Rio de Janeiro, Rio de Janeiro, Brasil
}

\begin{abstract}
RESUMO
Este artigo objetiva realizar uma aproximação entre os estudos de Francisco Varela - desenvolvidos no campo das ciências da cognição - e a psicologia clínica. Para tanto, fazemos um breve histórico das ciências da cognição, buscando esclarecer sua heterogeneidade. Com isso, procuramos diferenciar - cognitivismo e seu desdobramento na clínica (as Terapias Cognitivo Comportamentais) da abordagem proposta por Varela e as possíveis ressonâncias na clínica psicológica orientada pelos estudos de produção de subjetividade. Toma-se como base as ideias desenvolvidas por Varela em parceria com Humberto Maturana e aquelas elaboradas na abordagem enativa, tais como as noções de autopoiese, acoplamento estrutural, aprendizagem incorporada e breakdown. Busca-se aproximar tais noções dos conceitos de produção de subjetividade, agenciamentos, territorialização e desterritorialização, de Gilles Deleuze e Félix Guattari. O texto dá continuidade a uma discussão desenvolvida por Suely Rolni, Eduardo Passos e Regina Benevides de Barros, Virginia Kastrup, Jerusa Rocha e o próprio Guattari.
\end{abstract}

Palavras-chave: abordagem da enação, produção de subjetividade, psicologia clínica.

\section{ABSTRACT}

This article aims to produce an intersection between the studies of Francisco Varela - which are included in the cognitive sciences field - and the clinical psychology. For that purpose, we make a brief historic of the cognitive sciences, so that we make it's heterogeneity clear. By doing so, we attempt to establish the differences between the cognitivism and it's clinical approach (that is, the CBT) and, on the other hand, the approach proposed by Varela and it's possible resonances with a clinical psychology oriented by the subjectivity production studies. For that purpose, we will anchor our investigation Varela's first researches - with his partner Humberto Maturana - and later on, when he formulated the enactive approach. Therefore, we 
will expose briefly the notions of autopoiesis, structural coupling, embodied learning and breakdown, which we will try to conect with Gilles Deleuze's e Félix Guattari's concepts of production of subjectivity, assemblage, territorialization and deterritorialization. By doing so, we align ourselves with other authors that have already started this dialog, such as Suely Rolnik (2007), Rogério da Costa (1993), Eduardo Passos and Regina Benevides de Barros (2000), Virginia Kastrup (1995; 2000), Jerusa Rocha (1998). Even Guattari (1992) himself has commented on the possibility of an intersection between these studies.

Keywords: enaction approach, production of subjectivity, clinical psychology.

\section{RESUMEN}

El objetivo de este estudio es aproximar la investigación de Francisco Varela - desarrollada en el campo de las ciencias cognitivas - y la psicología clínica. Para ese fin, presentamos una breve historia de las ciencias cognitivas, intentando esclarecer su heterogeneidad. Así, tratamos de diferenciar el cognitivismo y su desdoblamiento en la clínica (las Terapias Cognitivas Conductuales) de la abordaje propuesta por Varela y las posibilidades de resonancia en la clínica orientada por los estudios de producción de subjetividad. Se tiene por base las ideas desarrolladas por Varela en colaboración con Humberto Maturana, y también las elaboradas en la abordaje enactiva, como las nociones de autopoiesis, acoplamiento estructural, aprendizaje corporizada e breakdown. Se busca aproximar esas nociones de los conceptos de producción de subjetividad, agenciamientos, territorialización y desterritorialización, de Gilles Deleuze y Félix Guattari. Este artículo da continuidad a una discusión desarrollada por Suely Rolnik (2007), Eduardo Passos y Regina Benevides de Barros (2000), Virginia Kastrup (1995; 2000), Jerusa Rocha (1998) y mismo Guattari (en una entrevista con Rogério da Costa en 1993).

Palavras-chave: abordaje de la enacción, producción de subjetividad, psicología clínica.

\section{I ntrodução}

Este artigo pretende pensar a conexão entre a abordagem da enação, de Francisco Varela, e a Psicologia Clínica. Formulada no campo das ciências cognitivas, essa abordagem se distancia do cognitivismo computacional e é profícua para pensar uma modalidade de intervenção na clínica psicológica pautada por uma atitude éticopolitica voltada para a sustentação das desestabilizações. Como contraponto, procuramos dialogar com as propostas da Terapia Cognitivo-Comportamental (TCC), cujo foco é a resolução dos sintomas e a mudança comportamental ${ }^{1}$. O objetivo do presente artigo é destacar as formulações de Varela que se articulam com uma proposta clinica orientada pelos estudos de produção de subjetividade. Nesse percurso, nos apoiaremos tanto na teoria da autopoiese - desenvolvida em seus estudos iniciais, com Humberto Maturana - quanto na abordagem da enação, elaborada na década de 1990, quando Varela já estava radicado na França. Embora haja 
diferenças entre as duas abordagens, elas se aproximam na medida em que são perpassadas pela ideia de circularidade fundamental e de co-engendramento entre organismo e mundo. Assim, nos basearemos nas noções de autopoiese, acoplamento estrutural, aprendizagem incorporada e breakdown, que procuraremos conectar com os conceitos de produção de subjetividade, agenciamentos, territorialização e desterritorialização, de Gilles Deleuze e Félix Guattari. Dessa forma, damos seguimento aos estudos de outros autores que buscaram realizar esse diálogo, tais Rolnik (2007), Barros e Passos (2000) e Rocha (1998). Até mesmo Guattari (1992) chegou a comentar a possibilidade de intercessão entre esses estudos.

\section{O cognitivismo computacional, a herança behaviorista e seu desdobramento clínico}

Quando pensamos em uma clínica psicológica orientada por estudos cognitivos, normalmente nos vêm à mente as Terapias CognitivoComportamentais (TCC). Entretanto, trata-se de uma conclusão apressada e imprecisa, pois os estudos sobre a cognição não são homogêneos, assim como os pressupostos de que partem. Como veremos adiante, pressupostos ontológicos distintos produzem maneiras diversas de compreender os sintomas psíquicos e, também, de atuar na clinica psicológica. Para esclarecer a heterogeneidade das ciências cognitivas, façamos um breve histórico do campo.

As ciências cognitivas surgem por volta de $1940^{2}$, tomando a máquina de Turing ${ }^{3}$ e a cibernética como bases para a compreensão da inteligência humana (Dupuy, 1996). Em meados dos anos 1950, elas começam a utilizar o computador como o modelo prototípico para entender a cognição humana. De acordo com o modelo computacional, a cognição é um complexo processamento de informações provenientes do meio, ou inputs, seguido pela emissão de respostas, isto é, outputs (Kastrup, 2013).

Segundo Rangé e Borba (2008), as Terapias CognitivoComportamentais (TCC) surgem no fim dos anos 1960, sendo em parte fruto do legado do cognitivismo computacional. No entanto elas têm uma dupla herança. Por um lado, derivam dos estudos sobre o comportamento desenvolvidos na esteira do behaviorismo, baseados no modelo estímulo-resposta. Por outro lado, a TCC pretende ampliar as possibilidades das técnicas comportamentais, destacando o papel dos processos cognitivos na determinação do comportamento. De acordo com Beck (1997), os comportamentos inadequados são o resultado de falhas no processamento da informação oriunda do meio devido à existência de esquemas mentais pouco adaptativos, isto é, não condizentes com a realidade. A clínica lança mão de protocolos 
de tarefas cognitivas, que são propostas pelo psicólogo. Por meio de tais tarefas, especificas, pré-definidas e realizadas por meio de treinos sistemáticos, visa-se produzir um alívio do sofrimento causado pelos sintomas, além de uma mudança comportamental e uma nova configuração da cognição. O esperado é que surjam novas regras de funcionamento da cognição, e que estas tragam comportamentos mais congruentes com a realidade (Beck, 1997; Falcone, 2013). Estas terapias visam à adaptação de um indivíduo a um meio, sem conferir relevo especial aos contextos histórico, social e familiar. Essas abordagens são individualistas, enfocando as relações entre cognição, afeto e comportamento apenas enquanto evidências que indicam o grau de adequação de um organismo ou sujeito ao meio.

Como observam Varela, Thompson e Rosch (1993), o cognitivismo computacional se ancora em três pressupostos. O primeiro diz respeito ao realismo, isto é, à crença em um mundo com características predefinidas. O realismo supõe a existência de um objeto cujas características interferem em um sujeito que é independente dele. O segundo pressuposto é o de que a nossa tarefa é representar internamente tais atributos do mundo fidedignamente. Finalmente, o terceiro é o de que existe um eu separado do mundo e que age sobre ele. O trecho a seguir, de Beck e Knapp (2008), evidencia a existência de todos estes pressupostos na TCC.

Ao longo de todo tratamento, utiliza-se a abordagem colaborativa e psicoeducativa, com experiências específicas de aprendizagem desenhadas com 0 intuito de ensinar os pacientes a: 1) monitorar e identificar pensamentos automáticos; 2) reconhecer as relações entre cognição, afeto e comportamento; 3) testar a validade de pensamentos automáticos e crenças nucleares; 4) corrigir conceitualizações tendenciosas, substituindo pensamentos distorcidos por cognições mais realistas; e 5) identificar e alterar crenças, pressupostos ou esquemas subjacentes a padrões disfuncionais de pensamento (Beck \& Knapp, 2008, p. 59, grifos nossos).

Percebemos o modelo cognitivo-comportamental parte de uma concepção de realidade como um mundo empírico previamente determinado, do qual adviriam os inputs. A cognição teria a função de processar os dados provenientes deste meio de modo acurado, levando a respostas (outputs) bem adaptadas. Dessa forma, seria possível testar a validade da relação entre os pensamentos e o mundo empírico, estabelecendo o seu grau de adequação. Por fim, uma vez identificados, os pensamentos "distorcidos", poderiam ser corrigidos, de modo a se adaptar a essa realidade que os antecede. 
Em contraposição ao cognitivismo computacional, temos a teoria da autopoiese, elaborada por Francisco Varela em parceria com o também biólogo Humberto Maturana. Ao invés de supor um sistema baseado em computadores e seus inputs e outputs, o modelo da autopoiese tem como base o ser vivo, entendido como possuindo uma organização eminentemente circular. Em outras palavras, não haveria determinismo nem por parte do meio nem do organismo. Em lugar disso, propõe que estes se criam mutuamente e incessantemente, em um processo de coengendramento. Posteriormente, Varela desenvolve a abordagem da enação. Essa realiza uma crítica radical ao cognitivismo, que incide sobre o pressuposto de que a cognição humana tem como fundamento a representação de um mundo existente a priori.

\section{Uma Cognição Autopoiética}

Em A Árvore do Conhecimento, Maturana e Varela (2001) afirmam que todos os seres vivos têm em comum 0 fato de serem autopoiéticos, isto é, eles têm como principal característica a produção de si mesmos. Os componentes de um sistema vivo participam de uma rede de interações que tem como efeito final a manutenção dessa mesma rede. Porém, como veremos, afirmar que um organismo produz a si mesmo não equivale a dizer que ele não depende do meio.

Para Maturana e Varela (2001), os seres vivos e seus meios são distintos, mas mutuamente dependentes: mudanças do meio podem provocar alterações nos organismos nele inseridos, enquanto as transformações internas dos sistemas vivos também podem modificar seu meio. Essas mudanças não ocorrem de modo determinístico, através de instruções (inputs), mas por meio de perturbações. Quaisquer interações com o meio geram perturbações e seus efeitos vão desde o desencadeamento de mudanças estruturais no organismo até o seu aniquilamento. A cognição diz respeito à capacidade de se unir a um mundo de significados compartilhados, de manter-se vivo, de criar um mundo. A essa capacidade, Maturana e Varela (2001) chamam de acoplamento estrutural.

É possível estabelecer uma aproximação dos termos acoplamento estrutural (Maturana \& Varela, 2001) e agenciamento (Deleuze, 2011; Guattari \& Rolnik, 1986). Os dois termos são intercambiáveis, uma vez que ambos se referem a uma comunicação direta, que não é mediada pela representação. Tanto o agenciamento quanto o acoplamento tratam de conexões que não se dão por meio de orientações, determinismos ou hierarquias, mas por perturbações (Kastrup, 2007). 
O acoplamento estrutural é uma dinâmica entre organismo e ambiente em que nada se passa com um que não afete o outro. Segundo Guattari (1992), o mesmo ocorre com a subjetividade, cujo constante diferenciar-se encontra-se em sintonia com tudo o que se passa no meio de que faz parte. Em tais encontros sofremos perturbações e somos forçados a pensar, a colocar novas questões. Essas mudanças ocorrem constantemente ao longo de nossas vidas, de modo que é impossível pensarmos em um eu imutável. O agenciamento não está no mesmo nível que as formas unificadas do sujeito e do objeto, mas em uma região em que coexistem diversos vetores - eles podem se conectar uns com os outros de diferentes modos, formando mecanismos de produção de subjetividade. Isso não significa que a subjetividade seja, simplesmente, determinada por condições históricas, pois ela surge e se molda no social, ao mesmo tempo em que atua sobre ele, produzindo novas conexões, transformando-o (Kastrup, 2007).

\section{Co-engendramento e produção de subjetividade}

O conceito de subjetividade não equivale ao de sujeito, pois, assim como o organismo autopoiético, ela supõe um processo incessante de produção: ela é produzida, fabricada e modelada. Guattari afirma que subjetividade é "o conjunto das condições que torna possível que instâncias individuais e/ou coletivas estejam em posição de emergir" (Guattari, 1992, p.19). No processo de produção de subjetividade, sujeito e objeto encontram-se co-engendrados. Esse conceito indica uma ruptura com as dicotomias sujeito-objeto, interior-exterior, indivíduo-sociedade. A subjetividade é múltipla, pois está para além do indivíduo, sendo composta por vetores materiais, políticos, tecnológicos, econômicos, sociais. Segundo Kastrup (2007), os estudos da produção de subjetividade não pretendem apontar para uma influência do meio sobre os sujeitos. A proposta, muito mais radical, é que tanto sujeito quanto objeto surgem de uma mesma rede de vetores que se transforma incessantemente.

Os estudos da produção de subjetividade são permeados pela recusa da existência de polos predefinidos e de uma relação de mútua influência, em favor da concepção de cocriação. Como Guattari e Rolnik (1986) apontam, a subjetividade é produzida por agenciamentos, isto é, relações entre componentes heterogêneos biológicos, sociais, maquínicos, históricos, tecnológicos, etc. - em que não há determinismo ou previsibilidade (Guattari \& Rolnik, 1986). Ela não opera por meio da interiorização de "coisas" que lhe são exteriores, na medida em que tais "coisas" formam as composições que constituem a produção de subjetividade. 
São exemplos de "coisas" desse tipo: um certo jeito de utilizar a linguagem, de se articular ao modo de semiotização coletiva (sobretudo da mídia); uma relação com o universo das tomadas elétricas, nas quais se pode ser eletrocutado; uma relação com o universo de circulação na cidade. Todos esses são elementos constitutivos da subjetividade. (Guattari \& Rolnik, 1986, p. 34).

Por sua vez, Varela pretende destacar que não há um sujeito que antecede o mundo, mas que a cognição emerge a partir da ação. Daí vem o conceito de enação, neologismo com base na palavra de origem inglesa enaction, que se refere a uma ação guiada pela percepção, e não pela representação (Varela et al., 1993): um saber que surge no próprio fazer. Assim, tanto para os estudos de produção de subjetividade quanto para Varela, o si mesmo não é um a priori, mas é efeito de certos modos de agenciamento ou acoplamento com o mundo. Varela et al. (1993), enfatizam a importância de se estar presente em cada experiência, isso é, vivenciando as situações com uma atenção concentrada e aberta ${ }^{4}$. Esse tipo de atenção possibilita que a experiência nos afete, seja gerando prazer, seja produzindo estranhamentos.

A subjetividade diz respeito aos modos de ser e estar no mundo e não há uma única maneira pela qual ela se configura. Segundo Guattari e Rolnik (1986), a filosofia e a psicologia sempre buscaram relacionar a subjetividade com uma identidade individual. Entretanto, para os autores, "não existe unidade evidente da pessoa: o indivíduo, - ego, ou, poderíamos dizer, a política do ego, a política da individuação da subjetividade é correlativa de sistemas de identificação que são modelizantes" (Guattari \& Rolnik, 1986, p.38). De acordo com essas abordagens, o indivíduo é um produto de uma rede de complexas operações.

Da mesma maneira, a existência de um eu como entidade organizadora e pré-existente é incompatível com a abordagem da enação, uma vez que esta implica uma circularidade que nos força a admitir a existência de uma rede de operações. Na abordagem da enação só há um sujeito na medida em que ele é fragmentado, não unificado (Varela et al., 1993). Se não há um organismo a priori, ou um meio a priori, como se poderia afirmar a existência de um si mesmo que governe a experiência? Para Varela, esse si mesmo seria o fruto de hábitos que consolidamos a partir da relação com o mundo - não sendo anterior aos processos cognitivos, tal qual um agente inalterável que fundamentaria as experiências. O si mesmo, portanto, está em uma relação de co-determinação com o mundo, assim como um caminho que vai se formando em uma floresta à medida que o percorremos. Nessas maneiras de se acoplar, tanto Varela quanto 
Guattari destacam que geralmente a experiência é relegada a um plano secundário:

A tendência atual é igualar tudo através de grandes categorias unificadoras e redutoras [...]. Toda criatividade no campo social e tecnológico tende a ser esmagada [...]. A experiência deixa de funcionar como referência para a criação de modos de organização do cotidiano (Guattari \& Rolnik, 1986, p.40).

Os estudos de Maturana e Varela influenciaram Guattari, que utiliza o termo autopoiese afirmando que el poderia ser "proveitosamente estendida às máquinas sociais, às máquinas econômicas e até mesmo às máquinas incorporais da língua, da teoria, da criação estética, etc." (Guattari, 1992, p.118). Podemos notar uma aproximação entre a cognição autopoiética e o conceito de produção de subjetividade, na medida em que ambos se referem a dinâmicas de criação descentralizadas, isto é, sem instância criadora, que oriente o processo. Nos dois, sujeito e objeto surgem a partir de seu coengendramento e são produzidos em um processo fundamentalmente circular, que não encontra seu início ou seu fim em nenhuma entidade pré-estabelecida. Não há qualquer caminho pré-definido, finalidade determinada (Kastrup, 1995) ou indivíduo originário evoluindo e agindo em um mundo que lhe é exterior.

\section{Aprendizagem incorporada e formação de territórios}

Como vimos, não há um si mesmo essencial, um eu mais profundo. A configuração que a subjetividade assume em dado momento se dá como um processo de conexão entre os múltiplos componentes que a atravessam o tempo todo. Entretanto, isso não quer dizer que antes reine um caos absoluto, que a subjetividade seja uma mera sucessão de estados aleatórios. Maturana e Varela (2001) buscaram tratar da relativa estabilidade dos organismos frente às perturbações constantes do meio com o uso da noção de clausura operacional (Maturana \& Varela, 2001). Entretanto, tal estabilidade não implica a manutenção inalterada das estruturas do organismo, pois alterações estruturais podem ser necessárias em face de determinadas perturbações.

Posteriormente, ao tratar da aprendizagem, Varela et al. (1993) evocam o exemplo do aprendizado da flauta. Um aprendiz do instrumento irá, em principio, comandar seus movimentos com a mente de acordo com regras que indicam as posições dos dedos. Nesse momento, suas ações são mediadas pela representação. Com a prática, o aprendiz diminui a distância entre a intenção de realizar um movimento e a ação propriamente dita: tocar flauta deixa de ser 
mental ou físico, e passa a envolver uma unidade mente-corpo. Em outras palavras, o aprendiz passa a estar em acoplamento direto com o instrumento. Os autores nomeiam essa forma de aprendizagem de encarnada ou incorporada.

Na linguagem de Deleuze e Guattari, (1997), podemos dizer que, mais do que decorar movimentos, o aprendiz constrói para si um novo território. Os territórios são composições que dizem respeito a uma relativa constância - assim como a aprendizagem incorporada de Varela. Mesmo com a incessante variação, existe algo que é mais ou menos estável, pois regras temporárias estão sempre se delineando. O que garante essa condição mínima de estabilidade é o território, que se constitui a partir de certa repetição e regularidade.

Eis que as forças do caos são mantidas no exterior tanto quanto possível, e o espaço interior protege as forças germinativas de uma tarefa a ser cumprida, de uma obra a ser feita. Há toda uma atividade de seleção aí, de eliminação, de extração, para que as forças íntimas terrestres, as forças interiores da terra, não sejam submersas, para que elas possam resistir, ou até tomar algo emprestado de caos através de filtro ou do crivo do espaço traçado (Deleuze \& Guattari, 1997, p. 116).

Conforme Guattari (1992) ressalta, os territórios podem ser delimitados por diversos meios. Em algumas sociedades, por exemplo, as danças, as máscaras e certas pinturas corporais que permeiam os seus rituais compõem determinados territórios existenciais. Eles são habitados com conforto e com presteza para a ação. Dentro de um território não precisamos refletir a todo momento sobre cada uma de nossas escolhas e temos o sentimento de "estar em casa". Em uma hipotética ausência de territórios não poderíamos antecipar nada. Nós nos encontraríamos em meio ao caos e tudo pareceria aleatório.

\section{Breakdown e desterritorialização}

No dia a dia, agimos segundo nossos hábitos e muitas de nossas ações não requerem qualquer esforço intelectual. Não pensamos quando acordamos, saímos da cama, cumprimentamos as pessoas que moram conosco, tomamos café da manhã... Contudo, há um tipo de experiência capaz de desconfigurar esse modo de agir corriqueiro. A essa experiência Varela dá o nome de breakdown (Varela, 2003). O conceito de breakdown sinaliza uma desestabilização da dinâmica autopoiética. Ele é vivido como um estranhamento, ou uma ausência momentânea de sentido. Frente a ele, acoplamentos estruturais e 
padrões de ação são questionados e podem se tornar obsoletos. Essa experiência nos faz sair de um modo de agir automatizado e recognitivo. Esse tipo de experiência pode nos acometer quando somos forçados a sair de nossos territórios existenciais, como quando terminamos um casamento que durou muitos anos. Por um lado, o breakdown nos destitui de nossa presteza e somos forçados a pensar, tomar decisões ou aprender novas ações. Por outro, ele gera uma abertura que possibilita a criação de novos acoplamentos e modos de operar. Assim, podemos nos reinventar, criando novas maneiras de viver.

Essa ruptura também parece presente em Guattari, ao indicar que, se, por um lado, nossa subjetividade é permeada por uma tendência à estabilização, por outro, ela também é composta por movimentos de desterritorialização. Segundo o autor, esses são geradores de "tensões de valor, relações de heterogeneidade, de alteridade, de devir outro" (Guattari, 1992, p.40). Um território entra em contato com novas forças constantemente, e estas são incorporadas aos traçados da subjetividade. I sso não implica, necessariamente, uma mudança dos contornos que ela assume. Porém, conforme tais mudanças se acumulam, a subjetividade se tensiona; a configuração que marcava certa subjetividade fica cada vez mais abalada, até que se atinge um certo limiar. Ocorre então um processo de desterritorialização, isto é, de desmanchamento de um território. No entanto, é preciso destacar que a desterritorialização nunca é total, pois isso implicaria a perda de toda e qualquer referência, de todos os territórios que habitamos, o caos completo.

Quando da desterritorialização, os contornos da subjetividade perdem seu valor, e ao tornarem-se obsoletos, somos convocados reinventálos. Como ressalta Rolnik (1999), "a subjetividade tende então a ser tomada por uma inquietude que a impele a tornar-se outra, de modo a dar consistência existencial para sua nova realidade" (Rolnik, 1999, p.208). É preciso destacar que para as abordagens clínicas ligadas aos estudos de produção de subjetividade, não se afirma que a saúde seja um estado de desestabilização constante. O mais fundamental é acolher a angústia da perda de si quando a mudança acontece, afinal, territorializações, desterritorializações e reterritorializações são movimentos que compõem a subjetividade. Como Rolnik (1999) ressalta, não se pode escapar deles - o que pode ser mais ou menos saudável são as maneiras pelas quais se lida com eles. Podemos tomar as desterritorializações como algo que impede que se viva de modo pleno e estável; por outro lado, pode-se vivê-la como condição de invenção da vida e de novos territórios. Uma situação desnorteadora e, até mesmo, aparentemente negativa pode levar à perda de um território existencial, mas também à abertura para novos campos de possível. 


\section{Descentramento do eu, crença e desejo}

Uma ideia comum às TCC é a de que haveria crenças nucleares, também denominados de esquemas. Percebemos em Beck e Knapp (2008) certa ambiguidade na conceituação das crenças nucleares que, aparecem ora como pensamentos enraizados e disfuncionais acerca de si e do mundo, ora como formas de organizar novas informações e de perceber o mundo. De um modo ou de outro, no entanto, as crenças nucleares estariam na raiz de interpretações distorcidas da realidade, na medida em que "modelam o estilo de pensamento de um indivíduo e promovem erros cognitivos encontrados na psicopatologia" (Beck \& Knapp, 2008, p. 57). As crenças interfeririam na capacidade de avaliar os eventos de modo objetivo, prejudicando o raciocínio, e são responsáveis por consequências de ordem fisiológica, emocional e comportamental. Podemos perceber, portanto, que a forma de inserção de um indivíduo em seu meio seria, em grande parte, atribuível às suas crenças nucleares.

Por sua vez, as abordagens clínicas orientadas pela produção de subjetividade assumem uma outra perspectiva sobre esse tema. Primeiramente, no lugar de crenças, elas tratam de desejo. O desejo não é um anseio ou apetite individual, nem algo emanado por um sujeito ou sequer o desejo por este ou por aquele objeto. O desejo não é algo que se passa em um si mesmo, como um teatro se desenrola em um palco vazio. Ele é definido por agenciamentos e por uma força que permite a criação de mundos e que nos põe em movimento, que produz interações múltiplas. “Desejar é construir um agenciamento, construir um conjunto, conjunto de uma saia, de um raio de sol" (Deleuze, n.d.). Assim, ele se dá em um mundo que ele mesmo constrói, produzindo conexões. Muito mais do que se orientar para determinado objeto, o desejo tem movimentos que levam à formação de territórios existenciais: ele produz o mundo ao pôr forças em relação. Dessa maneira, a análise do desejo não é redutível a um si mesmo.

Para essas abordagens clínicas, o desejo permeia todos os processos que constituem o viver, podendo desencadear processos que levam à estagnação e à perda de vigor ou aqueles que permitem a produção de ainda mais conexões e de agenciamentos que intensificam a vida. Assim, ele não é bom nem mau em si mesmo, mas pode gerar bons ou maus encontros. Segundo Neves (2009), é fundamental construir, através da própria experimentação, uma maneira de "selecionar" os movimentos do desejo que nos levem a uma ativação de nossa potência de agir. Essa seleção só pode se desenvolver através da experiência, de um tateio, encontro a encontro, experimentando os movimentos que provocam rupturas no que se encontrava cristalizado. 


\section{Desvitalização autopoiética e um sintoma na clínica}

Em face de perturbações constantes, os nossos contornos atuais da subjetividade podem se tornar antiquados - o que pode acontecer quando nos mudamos de cidade, por exemplo. Aos poucos, somos levados a delinear uma nova figura de subjetividade. No entanto, nesse momento de dissintonia paira um mal-estar (Rolnik, 1999). A necessidade de mudar produz desconforto e, em certas configurações, a subjetividade pode tentar frear o processo de produção de si, ou seja, a dinâmica autopoiética. A desaceleração dessa espécie de autopoiese ampliada não significa a morte biológica, mas uma desvitalização, em maior ou menor grau, da capacidade de criação de si.

Assim como Maturana e Varela (2001), Georges Canguilhem também toma a vida a partir da capacidade do organismo de estabelecer normas para si mesmo. Em O Normal e o Patológico (1990), ele afirma que a vida é uma atividade normativa, isto é, que cria novas regras constantemente - o que nos remete à noção de acoplamento estrutural, já explicitada. Para Canguilhem, a sanidade diz respeito à preservação da competência de se recriar e não a um ideal a ser alcançado. Por sua vez, a doença corresponde a uma redução da potência normativa, e não a um caos ou a uma desordem. Conforme ele ressalta, a doença está na incapacidade de criar novas regras (ainda que temporárias) para si mesmo (Canguilhem, 1990). O autor ainda destaca que "aquilo que é normal (...) em determinadas condições, pode se tornar patológico em outra situação, se permanecer inalterado" (Canguilhem, 1990, p.145). Conforme perdemos a capacidade de nos recriar, ficamos fixados em regras já estabelecidas e que não necessariamente estão em sintonia com as necessidades correntes de nossas vidas. Vivemos em uma espécie de nostalgia: estamos em uma situação do presente, mas gostaríamos de continuar vivendo como no passado. Por exemplo, podemos estar morando em uma metrópole, mas querendo viver como se habitássemos no interior, ou vice-versa. Nossa autonomia se enfraquece, nossa capacidade de produzir constantemente novas regras temporárias encontra-se restringida e ficamos carentes de potência produtiva (Rolnik, 2007).

Se, por um lado, a saúde é a capacidade normativa - ou autônoma - , por outro, a dificuldade de criar novas normas é vivida com sofrimento. Tal sofrimento advém do descompasso entre uma situação que demanda novos modos de enfrentamento e uma fixação em hábitos consolidados em torno de uma identidade. Agarramo-nos a uma identidade pré-definida ignorando as forças que perpassam o campo e nós mesmos. Entretanto, não podemos impedir o contato com forças que nos obrigam a mudar. Este conflito leva à produção de sintomas psíquicos, como Rolnik esclarece: 
Para nos proteger, fazemos sintomas (...). De um lado, [eles] neutralizam as diferenças, poupando-nos de enfrentar suas exigências (...). De outro lado, porém, esquivar-se tem seu custo: um desvigor do processo de construção experimental da existência, através da qual atualizam-se as diferenças. A doença psíquica é exatamente este desvigor (Rolnik, 1999, p.2).

Esse entrave da dinâmica autopoiética pode revelar-se de diversas maneiras, mas há uma importante forma que ele pode assumir, correspondendo a um fechamento muito rígido dessa capacidade normativa. Nesse caso, ocorre uma diminuição - em maior ou menor grau - dos processos de problematização. Esse sintoma aponta para uma identificação do sujeito com as regras já existentes, que são tomadas como leis que direcionam e restringem suas ações, embora sejam fruto de longos processos de criação. Os automatismos imperam - em detrimento dos processos de autopoiese. No entanto, o fechamento para a dinâmica autopoiética jamais é completo, de modo que sempre há a possibilidade de sofrer rupturas. Forças desestabilizadoras podem provocar desmanchamento dos territórios, das configurações relativamente estáveis, habituais. Experiências de breakdown podem romper com uma atitude recognitiva (Kastrup, 2007).

A clínica pode trabalhar no sentido de acolher e sustentar o estranhamento, a problematização de nossas relações atuais com o território que habitamos. Todavia, a clínica não orienta as mudanças que porventura aconteçam, no sentido de uma adaptação ótima. Ela acompanha a construção de novas configurações da subjetividade. Essas novas configurações não equivalem a um ajustamento da mente ao mundo, como na TCC, mas a uma recriação indissociável da subjetividade e do mundo.

Face à possibilidade de transformação, muitas vezes somos tomados pelo medo do fracasso e, assim, tais forças podem deixar de ser produtivas e as desestabilizações podem levar à paralisia (Rolnik, 1997). Acaba-se forçando uma estabilização antecipada - mesmo que geradora de sofrimento - e desvitalizando o processo de reinvenção de si, ou a autopoiese ampliada de que Guattari fala. Fecha-se cada vez mais para a mudança. Varela, Thompson e Rosch (1993) enfatizam que normalmente a ausência de um si mesmo é vivida como algo negativo, uma falta, e essa forma de encarar a inexistência de um "eu interior" pode levar ao desespero. "O medo de perder casas e coisas é nada em face do terror de perder a si mesmo" (Guattari \& Rolnik, 1986, p.63). O que geralmente se tenta fazer é buscar construir rapidamente um novo fundamento existencial. 
Tomando como inspiração Varela et al. (1993), podemos dizer que uma maior vitalidade significa estar presente na experiência, vivendo a partir de um estado de atenção, e não como um observador externo. Essa abertura é caracterizada pela possibilidade de se deixar afetar pela experiência - que pode, muitas vezes, provocar estranhamento e inquietação. Quando nos voltamos para nosso si mesmo, acabamos nos desligando daquilo que se passa entre nós e o mundo. Isto é, produzimos um afastamento entre mente e corpo; interrompemos nossa experiência de corpo presente (Rocha, 1998). Assim como Varela, Rolnik (2007) propõe que o apego à identidade carrega um sentido conservador, na medida em que tenta bloquear 0 encontro com o mundo - já que esse encontro comporta o risco de transformar-se. Pelo medo da desorientação, pode-se "anestesiar" essa capacidade de afetar/ser afetado. Com isso, impede-se a realização de diversas conexões, chegando-se a acreditar em um "dentro" em oposição a um "fora", que esse "dentro" é responsável por representar e sentir e, mais ainda, que se tem ou se é esse "dentro" (Rolnik, 2007).

Com relação à prática clínica, Rolnik (2007) destaca a importância de consideramos a existência de um "limiar de desterritorialização", que indica o quanto se suporta de desorientação. Orientar-se por essa "regra de ouro" permite que o psicólogo na clínica possa nortear sua intervenção sempre em nome da vida. Assim como o conceito de autopoiese nos fala de uma dinâmica orientada pela manutenção da vida (ainda que circunscrita à vida biológica), para Rolnik, a tarefa do psicólogo tem a mesma função: não busca promover a mera destruição de hábitos, devendo avaliar até que ponto as defesas utilizadas têm uma serventia no que concerne à proteção da vida, até que ponto são necessárias. Esse limiar aponta simultaneamente para o limite de tolerância subjetiva ao desmanchamento de territórios e para o quanto esse processo de desterritorialização é impedido, estagnado. O principal norteador para a atuação em psicologia clínica seria o de lembrar-se sempre de que esse limiar existe. Estando atentos para ele, é possível perceber os graus de perigo e potência de seus analisandos. Quando esse limiar é ultrapassado corre-se o risco de provocar algo como "pane no sistema", em que passa a haver uma defasagem entre os processos de desterritorialização e a construção de novos territórios.

\section{Considerações finais}

Como podemos observar em Beck (1997), as TCC são orientadas por protocolos de tarefas que pretendem produzir uma mudança nos comportamentos com vistas a obter uma melhor adaptação do paciente à situação enfrentada. Isso é realizado por meio de diversas 
técnicas, mais ou menos consolidadas e formuladas antes mesmo do encontro com o paciente. Entre tais técnicas, podem constar o agendamento e monitoramento de atividades, treino em habilidades sociais, a dessensibilização sistemática, entre outras. Neste tipo de intervenção clínica, supõe-se que o psicólogo é alguém mais capacitado, podendo instruir o paciente a realizar esta ou aquela tarefa a fim de obter uma percepção mais realista do mundo (Beck, 1997). A ideia da terapia como uma forma de educação está presente em Beck (1997), que além de nomear alguns dos exercícios propostos como "tarefas de casa", tal qual em uma escola, ainda afirma que estes servem para reforçar os "aspectos educacionais da terapia cognitiva" (p. 268). Cabe insistir que a formulação de tais protocolos parte do pressuposto de que há um mundo predeterminado ao qual o paciente se deve adequar, afinal, nas palavras de Beck (1997, p. 18), "as técnicas terapêuticas destinamse a identificar, testar no real e corrigir" as percepções distorcidas.

Ao pensarmos em uma clínica orientada pela abordagem da enação, rompe-se com uma concepção de analista e analisando, psicólogo e paciente, como unidades apartadas, e com identidades pré-definidas. No entanto, a clínica baseada nos estudos de produção de subjetividade supõe a codeterminação e o coengendramento de analista e analisando. É nessa reciprocidade que eles se produzem. Como não se ancora em um realismo, não busca uma adaptação do sujeito a uma realidade que the antecede e existe fora dele. Ao mesmo tempo, por recusar uma realidade independente do sujeito, não tem uma meta predefinida a ser alcançada. Sendo assim, essas abordagens não visam a promover uma mudança de comportamento em uma direção pré-determinada. Como Guattari (1992) afirma, essas abordagens são interessantes na medida em que possibilitam, para os analisandos, uma abertura para o surgimento de novas configurações e, para os analistas, um distanciamento de sistemas interpretativos fixos. Acima de tudo, a clínica é um espaço para problematizar hábitos engessados e provocar rachaduras em territórios cristalizados que estejam produzindo sofrimento psíquico. A partir dessas considerações, podemos pensar uma clínica que se relaciona com o campo das ciências cognitivas e que se distancia das práticas desenvolvidas pelas TCC. Estas buscam a solução das queixas trazidas pelo cliente a partir de um protocolo técnico, levando a uma mudança comportamental. Por sua vez, a clínica orientada pelos estudos de subjetividade incide sobre a experiência de problematização e não apenas sobre a solução de problemas, podendo levar à criação de novas dinâmicas de produção de si.

O psicólogo clínico atua como um catalisador de breakdowns iniciados pelo analisando, buscando possibilitar o surgimento de novos agenciamentos, novos acoplamentos (Guattari, 1992). Mais do que fórmulas e protocolos universais, o que está em jogo é manter-se 
atento às estratégias do desejo nos diferentes fenômenos da existência, buscando amplificar as conexões que ele estabelece. Nesse processo, o psicólogo não detém de antemão o saber que orienta o processo de mudança. É preciso acompanhar o traçado das linhas que sedentarizam e das que dinamizam, o desenrolar dos processos de territorialização, desterritorialização e reterritorialização. A função da clínica é justamente propiciar movimentos desejantes capazes de produzir novas conexões e novos mundos. É, portanto, uma clínica mais próxima de uma ética do que de uma pedagogia, que sustenta os movimentos de expansão da vida e de criação de novos sentidos.

\section{Referências}

Andrade, L. A. B., \& Silva, E. P. (2005). O conhecer e o conhecimento: comentários sobre o viver e o tempo. Ciências \& Cognição, 4, 35-41. Retrieved from http://www.cienciasecognicao.org

Barros, R. B., \& Passos, E. (2000). A construção do plano da clínica e o conceito de transdisciplinaridade. Psicologia: Teoria e Pesquisa, 16(1), 71-79. Retrieved from http://www.scielo.br/scielo. php?script=sci_arttext\&pid=S0102$37722000000100010 \& \operatorname{lng}=\mathrm{en} \& \mathrm{nrm}=$ iso

Beck, A. T., Rush, A. J., Shaw, B. F., \& Emery, G. (1997). Terapia Cognitiva da Depressão. Porto Alegre: Artes Médicas.

Beck, A., \& Knapp, P. (2008). Fundamentos, modelos conceituais, aplicações e pesquisa da terapia cognitiva. Revista Brasileira de Psiquiatria, 30(2), 54-64. Retrieved from http://www.scielo.br/scielo. php?script=sci_arttext\&pid=S1516$44462008000600002 \& \mathrm{lng}=$ en\&nrm $=$ iso

Canguilhem, G. (1990). O Normal e o Patológico. Rio de Janeiro: Forense Universitária.

Deleuze, G. (n.d.). O Abecedário Deleuze. Retrieved from <http://stoa.usp.br/prodsubjeduc/files/262/1015/Abecedario+ G. +Deleuze.pdf $>$.

Deleuze, G. (2011) Crítica e Clinica. São Paulo: Ed. 34.

Deleuze, G., \& Guattari, F. (1997). Kafka por uma literatura menor. Rio de Janeiro: I mago.

Dupuy, J. P. (1996). Nas Origens das Ciências Cognitivas. São Paulo: Editora da Universidade Estadual Paulista.

Eirado, A., \& Passos, E. (2004). A Noção de Autonomia e a Dimensão do Virtual. Psicologia em Estudo, 9(1), 77-85.

Falcone, E. (2013). As bases teóricas e filosóficas das abordagens cognitivo-comportamentais. In A. M. Jacó-Villela, A. A. L. 
Ferreira, \& F. T. Portugal (Orgs.), História da Psicologia: Rumos e percursos (pp. 223-242). Rio de Janeiro: Nau.

Guattari, F. (1992). Caosmose: um novo paradigma estético. Rio de Janeiro: Editora 34.

Guattari, F., \& Rolnik, S. (1986). Micropolíticas: cartografias do desejo. Petrópolis: Vozes.

Kastrup, V. (1995). Autopoiese e subjetividade: sobre o uso da noção de autopoiese por G. Deleuze e F. Guattari. Revista do Departamento de Psicologia da UFF, 7(1), 86-97.

Kastrup, V. (2007). A Invenção de Si e do Mundo: uma introdução do tempo e do coletivo no estudo da cognição. Belo Horizonte: Autêntica.

Kastrup, V. (2013). A psicologia no Contexto das Ciências Cognitivas. In A. M. Jacó-Villela, A. A. L. Ferreira, \& F. T. Portugal (Orgs.), História da Psicologia: Rumos e percursos (pp. 245-268). Rio de Janeiro: Nau.

Maturana, H., \& Varela, F. (2001). A Árvore do Conhecimento: as bases biológicas da compreensão humana, São Paulo: Palas Athena.

Neves, C. (2009). Gilles Deleuze e Política: interferências nos modos de se estar nos verbos da vida. In S. H. Tedesco \& M. L. Nascimento (Orgs.), Ética e subjetividade: novos impasses no contemporâneo (pp. 191-212). Porto Alegre: Sulinas.

Rangé, B., \& Borba, A. (2008). Vencendo o Pânico: terapia integrativa para quem sofre e para quem trata o transtorno de pânico e agorafobia. Rio de Janeiro: Cognitiva.

Rolnik, S. (1997). Toxicômanos de identidade: subjetividade em tempo de globalização. In D. Lins (Org), Cultura e subjetividade. Saberes Nômades (pp.19-24). Campinas: Papirus.

Rolnik, S. (2007) Cartografia sentimental: transformações contemporâneas do desejo. Porto Alegre: Sulina.

Rolnik, S. (1999). Novas figuras do contemporâneo. In L. Santaella \& J. A. Vieira (Orgs.), Caos e Ordem na Filosofia e nas Ciências (pp. 206-221) São Paulo: Face e Fapesp.

Rocha, J. M. (1998) Autopoiese e Subjetividade, algumas indicações para uma clínica. (Monografia de Pós-Graduação não publicada), Universidade Federal Fluminense, Niterói, RJ .

Varela, F. (n.d.). Conhecer: as ciências cognitivas tendências e perspectivas. Lisboa: Instituto Piaget.

Varela, F. (2003). O reencantamento do concreto. In Núcleo de Estudos e Pesquisas da Subjetividade - PUC-SP (Eds.). Cadernos de Subjetividade: O reencantamento do concreto ( $p p$. 71-86). São Paulo: HUCITEC EDUC.

Varela, F., Thompson, E., \& Rosch, E. (1993). The Embodied Mind, MIT Press, Cambridge, MA. 
Vasconcelos, C. (2004). A Existência como Dobras Infindáveis de Si Mesma: considerações sobre o si mesmo cognitivo na obra de Francisco Varela. (Dissertação de Mestrado não publicada). Programa de Pós-Graduação em Psicologia, Universidade Federal Fluminense, Niterói, RJ .

\section{Endereço para correspondência Veronica Torres Gurgel}

Universidade Federal do Rio de J aneiro - UFRJ

Av. Pasteur, 250 fundos, Praia Vermelha, CEP 22290-240, Rio de Janeiro - RJ, Brasil

Endereço eletrônico: vgurgel@gmail.com

\section{Virginia Kastrup}

Universidade Federal do Rio de J aneiro - UFRJ

Av. Pasteur, 250 fundos, Praia Vermelha, CEP 22290-240, Rio de Janeiro - RJ, Brasil

Endereço eletrônico: virginia.kastrup@gmail.com

Recebido em: 21/09/2105

Aceito em: 14/07/2017

\section{Notas}

* Doutoranda na Universidade Federal do Rio de Janeiro, Rio de Janeiro, Brasil. Titulação: mestre em psicologia (UFRJ).

** Professora na Universidade Federal do Rio de Janeiro, Rio de Janeiro, Brasil. Titulação: doutorado em Psicologia Clínica (PUC-SP).

${ }^{1}$ Embora também seja possível realizar um contraponto com a psicanálise, este não será contemplado no presente artigo.

2 Para este panorama das ciências cognitivas, consultar Dupuy (1996), Varela (n.d.); Varela, Thompson e Rosch, (1995), Vasconcelos (2004) e Kastrup (2013).

${ }^{3}$ Concebida na década de 1930 pelo matemático de mesmo nome, e um dispositivo imaginário capaz de realizar as mesmas operações que a mente humana, tendo lançado as bases para o surgimento do computador (Dupuy, 1996).

${ }^{4}$ Cf. Almeida, M.C., Carijó, F.H. e Kastrup, V. (2009) A abordagem da enação no campo da deficiência visual, Informática na educação: teoria \& prática, Porto Alegre, v.12, n.2, p. $114-122$.

Este artigo de revista Estudos e Pesquisas em Psicologia é licenciado sob uma Licença Creative Commons Atribuição-Não Comercial 3.0 Não Adaptada. 